\title{
Differential expression of acidic proteins with progression in the MCF10 model of human breast disease
}

\author{
NATHAN S. BUCHANAN ${ }^{1}$, JIA ZHAO ${ }^{1}$, KAN ZHU $^{3}$, TASNEEM H. PATWA ${ }^{1}$, \\ FRED R. MILLER ${ }^{4}$ and DAVID M. LUBMAN ${ }^{2}$
}

Departments of ${ }^{1}$ Chemistry, ${ }^{2}$ Surgery, The University of Michigan, Ann Arbor, MI; ${ }^{3}$ Novartis Institute for Biomedical
Research, Inc., Cambridge, MA; ${ }^{4}$ Barbara Ann Karmanos Cancer Institute, Wayne State University, Detroit, MI, USA

Received January 2, 2007; Accepted February 22, 2007

\begin{abstract}
A proteomic characterization of one premalignant (MCF10AT1) and two malignant (MCF10CA1a and MCF10 CA1d) human breast cancer cell lines has been performed using a combination of two-dimensional liquid separations and mass spectrometry. Chromatofocusing (CF) and NPS-RPHPLC are combined with ESI-TOF-MS to resolve and detect intact proteins. Simultaneously, fractions are collected and digested for protein identification using MALDI-MS peptide mass fingerprinting. Following protein identification a small database was compiled for use in comparison between IDs and measured masses taking into account variables such as pI, hydrophobicity and potential modifications. Out of 239 mass bands detected between $\mathrm{pH} 4.6$ and 6.0, 133 have been definitively associated with identified proteins and 67 show consistent up/down regulation in two malignant breast cancer cell lines relative to the precursor premalignant cell line. Of these, 8 are also altered in the premalignant MCF10AT1 cell line by treatment with estradiol. Differentially expressed proteins indicate significant changes to the cytoskeleton, cellular metabolism, and adaptation to environmental stressors in malignant cell lines.
\end{abstract}

\section{Introduction}

With breast cancer widely acknowledged as a major public health issue, scientists have long sought better, more detailed information about the changes at a cellular level that give rise to tumors. The genomic revolution has provided researchers with a number of tools for probing genetic information, from sequencing genes and locating mutations to mRNA expression profiling. While of great value for determining risk or categorizing tumors, these genetic and mRNA data provide only a partial picture of cell biology. The proteins encoded by these

Correspondence to: Dr Fred R. Miller, Barbara Ann Karmanos Cancer Institute, 10 E. Warren Ave., Detroit, MI 48236, USA

E-mail: millerf@karmanos.org

Key words: breast cancer, mass spectrometry, proteomics, twodimensional liquid separations genes, in their fully expressed and modified forms, are the molecules responsible for the final malignant nature of cancer cells.

Differential expression can be a result of disease, drug treatment, or differences between the cells such as imprecise tissue sampling or differences between cell lines. In the interest of isolating these differences to disease state or potential therapeutic treatments, the MCF10 xenograft model of human breast cancer was developed (1). Cell lines from this model encompass the entire range of human breast cancer progression from normal tissue to malignant, metastatic tumors. This work will describe differences in acidic protein expression between three of those cell lines, MCF10AT1 (AT1), MCF10CA1a.cl1 (CA1a) and MCF10CA1d.cl1 (CA1d). AT1 cells form simple ductular structures in immune deficient mice that eventually give rise to tumors in about $25 \%$ of the xenografts (2). Because progression is possible but not assured, AT1 represents a starting phenotype for progression. CA1a and CA1d are malignant lines derived from tumors originating from AT1 cells. CA1a and CA1d both represent aggressive late-stage phenotypes that lead to rapid tumor growth, morbidity, and metastases (3).

Various top-down proteomics techniques allow researchers to take snapshots of cellular protein expression and study different cellular or disease states. The two-dimensional liquid separation methodology employed here (4) compliments more traditional techniques, such as 2-D-polyacrylamide gel electrophoresis $(5,6)$, by providing similar information (protein molecular weight and $\mathrm{pI}$ ) together with improved compatibility with mass spectrometry. Cells are lysed and soluble intact proteins fractionated using chromatofocusing, a high-performance column based $\mathrm{pH}$ separation technique (7). Protein fractions are then separated by hydrophobicity using nonporous silica reverse phase high pressure liquid chromatography (NPS-RP-HPLC) in conjunction with electrospray ionization time-of-flight mass spectrometry (ESI-TOF-MS) and fraction collection for peptide mass fingerprinting (PMF) by matrix assisted laser desorption ionization time-of-flight mass spectrometry (MALDI-TOF-MS) (8). The end result is an annotated map of protein expression that provides mass, $\mathrm{pI}$ and identity. From this map differential protein expression can be quantified for biomarker elucidation.

Previous studies involving these cell lines (9) employed the Bio-Rad Rotofor ${ }^{\mathrm{TM}}$ pI separation technique. Although useful 
for separating preparative quantities of proteins, this approach was susceptible to significant protein overlap and subsequent analyses were often complicated by the complex run buffer employed. In addition, recent advances in automated data analysis $(10,11)$ have allowed a more thorough analysis of several adjacent fractions. As such this work will be the first to compare a broad pI range for MCF10 cells comparing malignant phenotypes (CA1a and CA1d) against an early stage of progression (AT1).

\section{Materials and methods}

Cell culture and lysis. CA1a and CA1d cells were grown as monolayers on plastic in Dulbecco's modified Eagle's medium (DMEM)/F12 medium supplemented with 5\% horseserum, $10 \mathrm{mM}$ N-2-hydroxyethylpiperazine-N-2-ethanesulfonic acid (HEPES) (pH 7.2). Because the premalignant AT1 cells are not as growth factor independent as are the malignant cells, medium for AT1 growth was further supplemented with $10 \mu \mathrm{g} / \mathrm{ml}$ insulin, $20 \mathrm{ng} / \mathrm{ml}$ epidermal growth factor, and $0.5 \mu \mathrm{g} / \mathrm{ml}$ hydrocortisone. Adherent cells were harvested in log phase ( $75-80 \%$ confluence). The growth medium was aspirated; the cells were gently washed with sterile phosphate buffered saline ( $\mathrm{pH} 7.4)$, scraped with a rubber policeman, and stored at $-80^{\circ} \mathrm{C}$ until analysis.

Frozen cell pellets were thawed in $1 \mathrm{ml}$ of lysis buffer containing 7.5 M urea, 2.5 M thiourea, 2\% w/v B-octylglucopyranoside, $2 \mathrm{mM}$ phenylmethylsulphonylfluoride, $10 \%$ v/v glycerol (all from Sigma-Aldrich, St. Louis, MO, USA) and $10 \mathrm{mM}$ Tris (2-carboxyethyl)phosphine hydrochloride (TCEP) (Pierce Biotechnology, Rockford, IL, USA). Cells were then vortexed for $2 \mathrm{~min}$ and lysed over $1 \mathrm{~h}$ at room temperature with occasional vortexing. The soluble protein fraction was separated from cell debris via centrifugation at $25,000 \mathrm{x} \mathrm{g}$ for $30 \mathrm{~min}$. In order to facilitate buffer exchange and removal of $\beta$-octyl-glucopyranoside, Tris and other potential interference, the supernatant was then diluted to $3 \mathrm{ml}$ with the CF start buffer described below. The sample was then loaded into an Amersham Bioscience PD-10 column (Piscataway, NJ, USA), pre-equilibrated with the start buffer according to the manufacturer's instructions. Start buffer was then added to the column in seven $0.5 \mathrm{ml}$ aliquots, the first aliquot was discarded, and the remaining effluent collected for quantitation. Combined eluent was quantified using a Bradford-type protein assay (Bio-Rad, Hercules, CA, USA) and a Shimadzu UV-1601 Spectrophotometer (Columbia, MD, USA). Bovine serum albumin standards (Sigma) were prepared from $0.17 \mathrm{mg} / \mathrm{ml}$ to $1.4 \mathrm{mg} / \mathrm{ml}$ in start buffer and analyzed in duplicate at $595 \mathrm{~nm}$ alongside the eluent according to the manufacturer's instructions. Eluent was stored at $-80^{\circ} \mathrm{C}$ unless immediately followed by first dimension (pI) separation.

Chromatofocusing. First dimension (pI) separations were carried out on a Beckman System Gold (Beckman-Coulter Fullerton, CA, USA) using a Beckman-Coulter PS-CF column equilibrated at room temperature with the start buffer containing $6 \mathrm{M}$ urea and $25 \mathrm{mM}$ bis-tris propane adjusted to pH 7.4 using saturated iminodiacetic acid (all Sigma). The separation was monitored by UV absorbance at $280 \mathrm{~nm}$ and
$\mathrm{pH}$ using an inline flow cell (Lazar Systems, Los Angeles, CA). Using results from the protein assay between 4 and $5 \mathrm{mg}$ of soluble protein were loaded on the column. Once the UV absorbance and $\mathrm{pH}$ data stabilized, elution buffer containing $6 \mathrm{M}$ urea and 10\% (v/v) Polybuffer 74 (Amersham) was introduced to the column at $0.2 \mathrm{ml} / \mathrm{min}$, creating the $\mathrm{pH}$ gradient that drives the separation. Fractions were collected manually every $0.2 \mathrm{pH}$ units until the lower $\mathrm{pH}$ limit $(\sim 4)$ was reached. Fractions were then frozen at $-80^{\circ} \mathrm{C}$ pending analysis and the column was washed sequentially with $1 \mathrm{M}$ $\mathrm{NaCl}$, deionized water, and isopropanol to remove any noneluted protein.

NPS-RP-HPLC and ESI-TOF-MS. Non-porous-silica reverse phase HPLC (NPS-RP-HPLC) separations were carried out on a $33 \times 4.6 \mathrm{~mm}$ Beckman-Coulter NPS-C18 column and Beckman Gold HPLC (Beckman-Coulter) connected to a Micromass/Waters LCT ESI-TOF-MS (Milford, MA). Prior to analysis, the $\mathrm{pH}$ of each fraction was verified using a minielectrode (Fisher) and $1 \mu \mathrm{g}$ bovine insulin (Sigma, MW=5435) was added to the samples as an internal standard. LCT mass calibration was performed externally using a NaI/CsI standard, yielding a mass accuracy of $\sim 200$ ppm for intact proteins. Separations use a water/acetonitrile gradient at $0.5 \mathrm{ml} / \mathrm{min}$ with $0.1 \%$ trifluroacetic acid and $0.3 \%$ formic acid modifiers (Sigma) as well as the following gradient; prerun 5\% B; 0 min, $15 \% \mathrm{~B} ; 1 \mathrm{~min}, 25 \% \mathrm{~B} ; 3 \mathrm{~min}, 31 \% \mathrm{~B} ; 6 \mathrm{~min}, 41 \% \mathrm{~B} ; 16 \mathrm{~min}$, $47 \% \mathrm{~B} ; 19 \mathrm{~min}, 67 \% \mathrm{~B} ; 23 \mathrm{~min}, 100 \% \mathrm{~B} ; 24 \mathrm{~min}, 100 \% \mathrm{~B}$; $27 \mathrm{~min}, 5 \% \mathrm{~B}$. Blank gradients were run between separations to reduce carryover. Effluent from the column was split with a Quick-Split flow splitter (Analytical Scientific Instruments, El Sobrante, CA) directing $0.3 \mathrm{ml} / \mathrm{min}$ to the UV detector for fraction collection and $0.2 \mathrm{ml} / \mathrm{min}$ to the LCT for intact mass determination. Individual peaks, absorbance maxima as identified by users at $280 \mathrm{~nm}$, were isolated with a fraction collector (Beckman model SC100) controlled by in-house data acquisition software.

Analyses of ESI-TOF-MS data were carried out with Protein Trawler (BioAnalyte, Inc., South Portland, ME) in conjunction with Masslynx 4.0 (Waters). Trawler automates integration and deconvolution of LC-MS datasets providing retention time, mass and intensity data for intact proteins. Chromatograms were integrated in 45 -sec time segments, and the mass range between 800 and $3200 \mathrm{Da}$ was deconvoluted from 4 to $75 \mathrm{kDa}$ with $2 \mathrm{Da}$ resolution. Deconvoluted peak intensities were normalized against the insulin internal standard intensity for each chromatogram. Corrected mass lists were then converted into 2-D mass maps using ProteoVue and DeltaVue (Beckman-Coulter).

MALDI-TOF-MS/PMF. Prior to digestion HPLC fractions were concentrated to $\sim 80 \mu \mathrm{l}$ using a SpeedVac (LabConCo, Kansas City, MO, USA), then neutralized with 20-60 $\mu 11 \mathrm{M}$ $\mathrm{NH}_{4} \mathrm{HCO}_{3}$ (depending on the original fraction volume). Collected fractions were digested overnight at $37^{\circ} \mathrm{C}$ using $0.5 \mu \mathrm{g}$ sequencing grade modified porcine trypsin (Promega, Madison, WI, USA). Following digestion, peptides were concentrated to $\sim 20 \mu \mathrm{l}$ using the SpeedVac. Peptides were then desalted using C18 ZipTip ${ }^{\mathrm{TM}}$ solid phase extraction micropipette tips (Millipore, Billerica, MA, USA). Peptides 


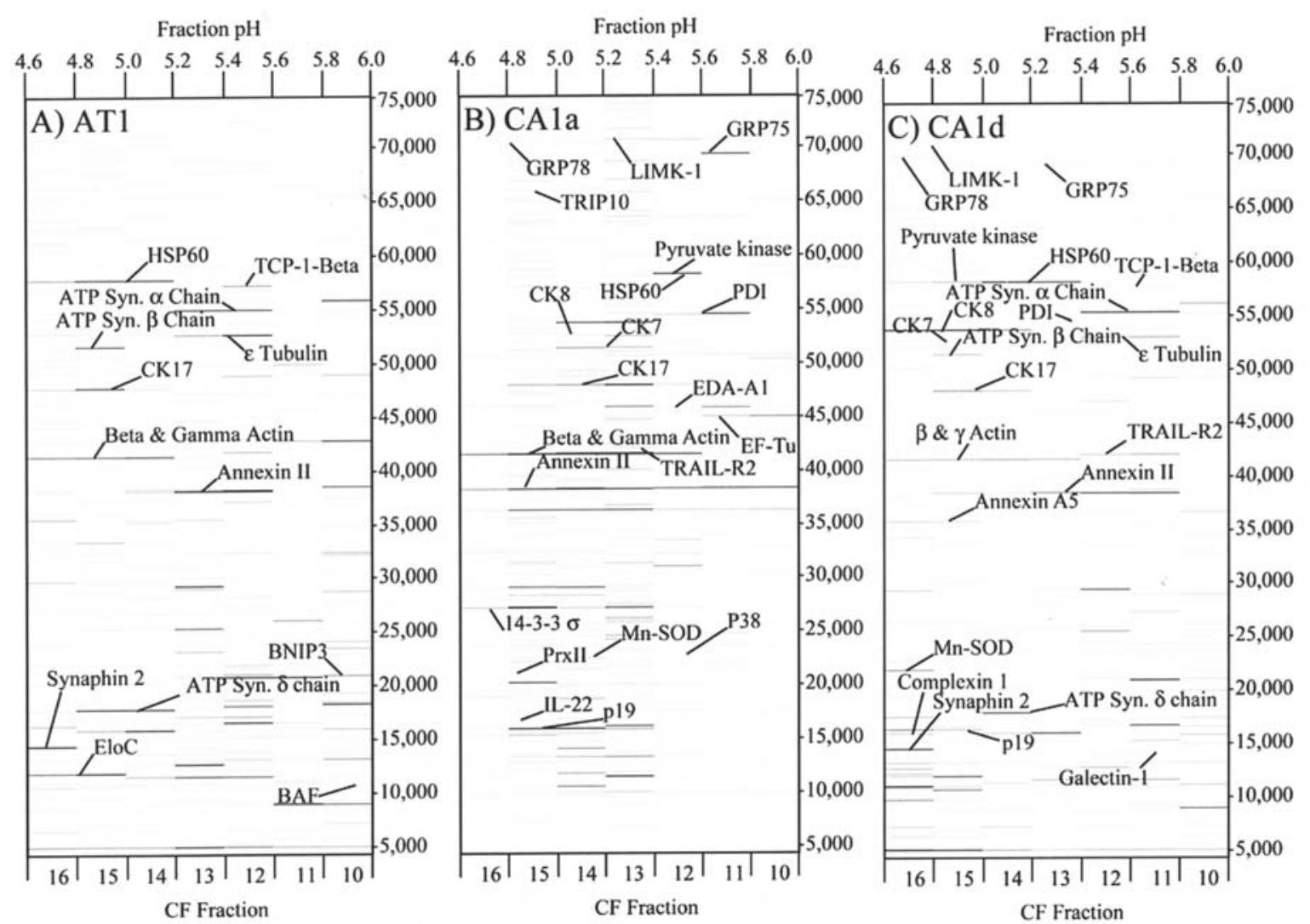

Figure 1. 2-D mass maps of MCF10 cell lines in pH 4.6-6.0 with some protein IDs labeled. A, MCF10AT1; B, MCF10CA1a; C, MCF10CA1d.

were extracted according to manufacturer's instructions and eluted into $7 \mu \mathrm{l}$ of $60: 40 \mathrm{MeCN}: \mathrm{H}_{2} \mathrm{O}$ with $0.1 \%$ trifluroacetic acid.

Desalted peptide $(2 \mu \mathrm{l})$ was co-crystallized on a MALDI target along with $1 \mu 1$ of an internal standard/matrix solution containing a 1:3 dilution of saturated $\alpha$-cyanohydroxycinnamic acid, $0.1 \mu \mathrm{g}$ of angiotensin (MW=1296 Da), $0.5 \mu \mathrm{g}$ adrenocorticotropic hormone peptides 1-16 (MW=2093 Da), and $0.5 \mu \mathrm{g}$ adrenocorticotropic hormone peptides 16-37 (MW=2465), all from Sigma. The target was allowed to air dry before introduction into the source region of a Micromass TofSpec2E MALDI-TOF-MS. Between 20 and 30 spectra were acquired and integrated for each sample. When possible a linear internal calibration was performed using the three peptide standards, if those peptides were suppressed a 'lock mass' spot can be employed to provide a pseudo-internal calibration. True internal calibration routinely yields mass accuracy of $20 \mathrm{ppm}$ or better, with slightly lower mass accuracy for lockmass calibration.

Lists of peptide masses were generated using MassLynx 4.0 and submitted to Protein Prospector (12) for comparison against the SwissProt database (13). Searches were carried out with the following limits: mammals only, pI: 1-10, mass accuracy $=50 \mathrm{ppm}$, missed cleavages $=2$, unmodified cystiene, possible modifications $=$ phosphorylation, acetylation, and methonine oxidation. Results with MOWSE scores $>1000$ and percent coverage $>20 \%$ were generally considered good matches for this technique. Given the degree of coelution observed in the second dimension separations unmatched peptides were searched for additional matches. Identities were then organized by molecular weight and their SwissProt database entries searched for potential isoforms and modifications. Because modifications, isoforms, and alternative splices were extremely common in eukaryotic systems, this step was essential for mass/ID correlation. Relying primarily on published isoforms, as well as post-translational modifications suggested by mass differences, the annotated list of theoretical molecular weights was used to create a final annotated virtual 2-D gel and list of differentially expressed proteins.

\section{Results}

Utilizing LC-MS data sets, mass maps (Fig. 1) were created for AT1, CA1a, and CA1d. These maps were then normalized internally using insulin standards, and against one another based on total protein loading for a given CF run. Datasets were then compared against one another manually in $10 \mathrm{kDa}$ increments looking for significant common features using DeltaVue. The resulting list of differentially expressed masses was then compared against a database of annotated MALDIPMF results with respect to theoretical MW, potential posttranslational modifications, $\mathrm{pI}$, and \% $\mathrm{B}$. In cases where a protein was not present in one of the cell lines, the lowest overall reportable value (100 counts) was used for purposes of comparison.

Proteins listed in Tables I and II are present in at least two cell lines and are correlated to a confident ID and mass. In several instances, isoforms and post-translational modifications were detected that could not have been identified without the mass resolution of ESI-TOF. Acetylations (+42 Da) appear to 
Table I. Proteins up-regulated in malignant MCF10CA1 cell lines. ${ }^{\mathrm{a}}$

\begin{tabular}{|c|c|c|c|c|c|}
\hline \multirow[b]{2}{*}{$\begin{array}{l}\text { Exp. } \\
\text { MW }\end{array}$} & \multicolumn{4}{|c|}{ Difference } & \multirow[b]{2}{*}{ Protein name (+ modifications) } \\
\hline & $\begin{array}{l}\text { Theo. } \\
\text { MW }\end{array}$ & CA1a & CA1d & $\begin{array}{c}\text { Accession } \\
\text { number }\end{array}$ & \\
\hline 16834 & 16829 & 995 & 105 & Q9GZX6 & Interleukin-22 precursor (IL-22) \\
\hline 16874 & 16871 & 394 & 30 & Q9GZX6 & IL-22 + acetyl \\
\hline 68771 & 68759 & 373 & 17 & P38646 & Stress-70 protein, mitochondrial precursor (GRP75) (Mortalin) + acetyl \\
\hline 29602 & 29598 & 286 & 60 & P25786 & PROS-30 \\
\hline 54308 & 54298 & 235 & 33 & P30101 & Protein disulfide isomerase A3 precursor (ERp60) + acetyl \\
\hline 45866 & 45856 & 216 & 10 & Q9UNE0 & $\begin{array}{l}\text { Tumor necrosis factor receptor superfamily member EDAR precursor } \\
\text { (EDA-A1 receptor) }\end{array}$ \\
\hline 17103 & 17101 & 189 & 46 & O95257 & Growth arrest and DNA-damage-inducible protein GADD45 $\gamma+$ phos \\
\hline 51340 & 51367 & 165 & 104 & P08729 & Keratin, type II cytoskeletal 7 (cytokeratin 7) (K7) (CK7) (sarcolectin) + phos \\
\hline 45944 & 45936 & 130 & 13 & Q9UNE0 & EDA-A1 receptor + phos \\
\hline 74810 & 74798 & 61 & 2 & P23469 & Protein-tyrosine phosphatase $\varepsilon$ precursor $(\mathrm{R}-\mathrm{PTP}-\varepsilon)$, isoform $2+$ GlcNAc \\
\hline 16429 & 16426 & 51 & 135 & O95881 & Thioredoxin-like protein p19 precursor (endoplasmic reticulum protein ERp19) \\
\hline 23223 & 23236 & 40 & 30 & Q9Y3B8 & Oligoribonuclease, mitochondrial precursor (CGI-114), isoform 2 \\
\hline 42204 & 42203 & 37 & 31 & O14763 & $\begin{array}{l}\text { Tumor necrosis factor receptor superfamily member } 10 \mathrm{~B} \text { precursor } \\
\text { (TRAIL-R2), long form }\end{array}$ \\
\hline 22283 & 22284 & 33 & 144 & P04179 & Superoxide dismutase $(\mathrm{Mn})$, mitochondrial precursor + phos \\
\hline 12768 & 12779 & 32 & 19 & P04436 & T-cell receptor $\alpha$ chain V region HPB-MLT precursor + acetyl \\
\hline 55829 & 55790 & 31 & 7 & Q13043 & Serine/threonine protein kinase 4 (MST-1) +3 phos \\
\hline 58017 & 58015 & 26 & 83 & P14618 & Pyruvate kinase, $\mathrm{M} 1$ isozyme (CTHBP) \\
\hline 63087 & 63091 & 22 & 3 & Q02383 & Semenogelin II precursor $($ SGII $)+2$ phos \\
\hline 72683 & 72681 & 21 & 2 & P53667 & LIM domain kinase 1 (LIMK-1) \\
\hline 23980 & 23980 & 21 & 11 & P05814 & B-casine presursor + acetyl \\
\hline 26810 & 26788 & 20 & 3 & P51858 & Hepatoma-derived growth factor \\
\hline 25477 & 25492 & 18 & 4 & Q8WUJ0 & $\begin{array}{l}\text { Serine/threonine/tyrosine interacting protein (protein tyrosine phosphatase- } \\
\text { like protein) }\end{array}$ \\
\hline 45109 & 45106 & 16 & 10 & Q96LI6 & Heat shock transcription factor, Y-linked (HSF2-like) \\
\hline 36836 & 36844 & 14 & 6 & P42330 & Aldo-keto reductase family 1 member $\mathrm{C} 3$ \\
\hline 73717 & 73709 & 14 & 7 & P42680 & Tyrosine-protein kinase Tec +1 phos \\
\hline 68028 & 68041 & 13 & 3 & Q9H2D6 & TRIO and F-actin binding protein (protein tara) \\
\hline 64604 & 64591 & 13 & 2 & P12035 & $\begin{array}{l}\text { Keratin, type II cytoskeletal } 3 \text { (cytokeratin } 3)(\mathrm{K} 3)(\mathrm{CK} 3)(65 \mathrm{kDa} \\
\text { cytokeratin) + phos }\end{array}$ \\
\hline 66504 & 66489 & 13 & 3 & P20700 & Lamin $\mathrm{B} 1+$ phos \\
\hline 19957 & 19953 & 12 & 6 & P01570 & Interferon $\alpha-14$ precursor (interferon $\alpha-\mathrm{H})$ (LeIF H) \\
\hline 64519 & 64511 & 12 & 4 & P12035 & Keratin, type II cytoskeletal 3 (cytokeratin 3) (K3) (CK3) (65 kDa cytokeratin) \\
\hline 53620 & 53623 & 11 & 8 & P05787 & Keratin, type II cytoskeletal 8 (cytokeratin 8$)(\mathrm{K} 8)(\mathrm{CK} 8)+$ phos \\
\hline 69642 & 69633 & 11 & 2 & O60506 & Heterogeneous nuclear ribonucleoprotein Q (hnRNP Q) \\
\hline 26456 & 26428 & 10 & 5 & P21266 & Glutathione S-transferase Mu 3 (GSTM3-3) (GST class-mu 3) (hGSTM3-3) \\
\hline 20725 & 20733 & 9 & 11 & P80188 & Neutrophil gelatinase-associated lipocalin precursor (NGAL) (P25) \\
\hline 34124 & 34095 & 9 & 3 & P06493 & Cell division control protein 2 homolog (p34 protein kinase) (CDK1) \\
\hline 47971 & 47974 & 9 & 2 & Q04695 & Keratin, type I cytoskeletal 17 (cytokeratin 17) (K17) (CK17) (39.1) \\
\hline 71420 & 71431 & 9 & 7 & Q16549 & Proprotein convertase subtilisin/kexin type 7 precursor + isoform + phos \\
\hline 72711 & 72681 & 9 & 3 & P53667 & LIMK-1 + phos \\
\hline 54324 & 54314 & 8 & 2 & P30101 & Protein disulfide isomerase A3 precursor (ERp60) + acetyl + Mox \\
\hline 19320 & 19340 & 6 & 2 & P20827 & Ephrin-A1 precursor (EPH-related receptor tyrosine kinase ligand 1) (LERK-1) \\
\hline 73781 & 73789 & 6 & 4 & P42860 & Tyrosine-protein kinase Tec +2 phos \\
\hline 70527 & 70521 & 6 & 34 & P11021 & $78 \mathrm{kDa}$ glucose-regulated protein precursor (GRP78) \\
\hline 21901 & 21892 & 5 & 2 & P32119 & Peroxiredoxin 2 (thioredoxin peroxidase 1$)$ \\
\hline 68823 & 68801 & 4 & 4 & P38646 & GRP75 + 2 acetyl \\
\hline 59699 & 59671 & 3 & 2 & P48643 & T-complex protein $1, \varepsilon$ subunit $(\mathrm{TCP}-1-\varepsilon)(\mathrm{CCT}-\varepsilon)$ \\
\hline 50029 & 50094 & 3 & 10 & Q9NY65 & Tubulin $\alpha-8$ chain $(\alpha$-tubulin 8$)$ \\
\hline 11649 & 11665 & 2 & 8 & P05387 & $60 \mathrm{~S}$ acidic ribosomal protein $\mathrm{P} 2$ \\
\hline 12504 & 12473 & 2 & 3 & Q15369 & Transcription elongation factor B polypeptide 1 (elongin C) (EloC) \\
\hline 20634 & 20645 & 2 & 2 & O96000 & $\begin{array}{l}\text { NADH-ubiquinone oxidoreductase PDSW subunit (complex I-PDSW) } \\
\text { (CI-PDSW) }\end{array}$ \\
\hline 12811 & 12821 & 2 & 5 & P04436 & HPB-MLT + 2 acetyl \\
\hline 14771 & 14758 & 2 & 5 & O15540 & Fatty acid-binding protein, brain (B-FABP) (brain lipid-binding protein) (BLBP) \\
\hline
\end{tabular}

${ }^{a}$ Experimental molecular weights, theoretical molecular weights, fold differences relative to MCF10AT1, accession numbers, and protein name with detected post-translational modifications are indicated. 
Table II. Proteins down-regulated in malignant MCF10CA1 cell lines. ${ }^{a}$

\begin{tabular}{|c|c|c|c|c|c|}
\hline \multirow[b]{2}{*}{$\begin{array}{l}\text { Exp. } \\
\text { MW }\end{array}$} & \multicolumn{4}{|c|}{ Fold difference } & \multirow[b]{2}{*}{ Protein name (+ modifications) } \\
\hline & $\begin{array}{l}\text { Theo. } \\
\text { MW }\end{array}$ & CA1a & CA1d & $\begin{array}{l}\text { Accession } \\
\text { number }\end{array}$ & \\
\hline 20651 & 20655 & -2 & -6 & P62256 & Ubiquitin-conjugating enzyme E2 H (ubiquitin-protein ligase $\mathrm{H}$ ) \\
\hline 62683 & 62681 & -2 & -10 & P31948 & $\begin{array}{l}\text { Stress-induced-phosphoprotein } 1 \text { (STI1) (Hsp70/Hsp90-organizing protein) + } \\
\text { acetyl }\end{array}$ \\
\hline 29478 & 29543 & -2 & -39 & P06748 & Nucleophosmin, isoform 2 \\
\hline 32621 & 32617 & -5 & -14 & P06748 & Nucleophosmin (NPM), isoform $1+$ acetyl \\
\hline 44454 & 44460 & -6 & -4 & Q8NBS9 & Thioredoxin domain containing protein 5 precursor (thioredoxin-like protein $\mathrm{p} 46$ ) \\
\hline 51849 & 51849 & -6 & -10 & P06576 & ATP synthase $\beta$ chain, mitochondrial precursor active form + phos \\
\hline 18451 & 18444 & -6 & -3 & O75947 & ATP Syn D + 2 acetyl \\
\hline 71372 & 71396 & -10 & -5 & P11021 & $78 \mathrm{kDa}$ glucose-regulated protein precursor (GRP78), isoform \\
\hline 35962 & 35967 & -17 & -3 & Q99729 & Heterogeneous nuclear ribonucleoprotein A/B (hnRNP A/B) \\
\hline 32851 & 32851 & -20 & -8 & P07951 & Tropomyosin $ß$ chain (tropomyosin 2) (ß-tropomyosin) \\
\hline 24628 & 24610 & -33 & -33 & P14678 & Small nuclear ribonucleoprotein associated proteins B and B' (snRNP-B) \\
\hline 50183 & 50151 & -37 & -4 & Q9Y6N5 & Tubulin $\alpha-1$ chain $(\alpha$-tubulin 1$)$ \\
\hline 21541 & 21541 & -41 & -36 & Q12983 & BCL2/adenovirus E1B 19-kDa protein-interacting protein 3 (BNIP3) \\
\hline 26575 & 26580 & -42 & -3 & P60174 & Triosephosphate isomerase (TIM) + acetyl \\
\hline 56024 & 56009 & -154 & -154 & P00367 & Glutamate dehydrogenase 1 , mitochondrial precursor (GDH) \\
\hline 55208 & 55209 & -204 & -4 & P25705 & ATP synthase $\alpha$ chain, mitochondrial precursor \\
\hline
\end{tabular}

${ }^{a}$ Experimental molecular weights, theoretical molecular weights, fold differences relative to MCF10AT1, accession numbers, and protein name with detected post-translational modifications are indicated.
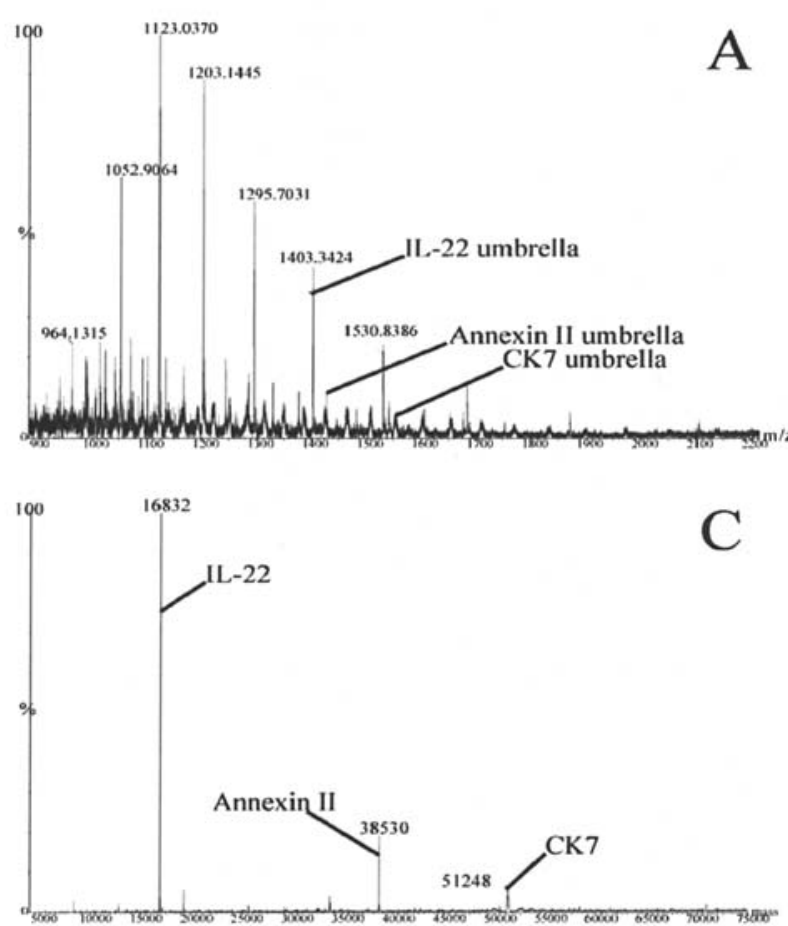

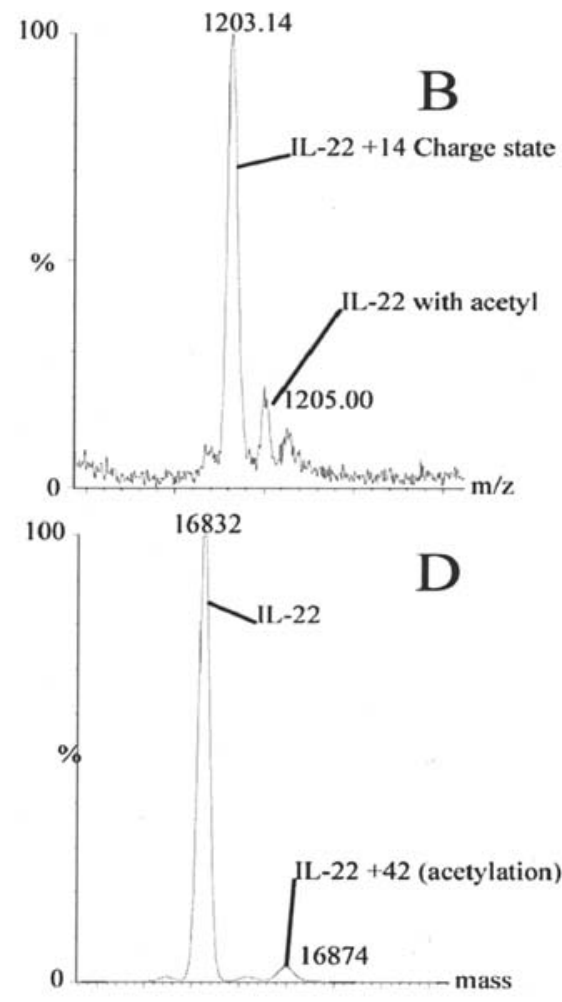

Figure 2. Acetylation of IL-22. A, Raw m/z spectrum of IL-22 and co-eluting proteins. B, Enlargement of labeled IL-22 peak showing acetylation. C, Deconvoluted mass and intensity of IL-22. D, Enlargement of IL-22 intact mass peak showing main peak and +42 Da mass shift of the probable acetylation.

be quite common, more so than suggested by either the protein databases or MALDI-PMF results. One example of such an acetylation is shown in Fig. 2 for IL-22. Although the MALDI-
PMF spectrum for IL-22 (not shown) does not indicate an acetylated peptide, all other important criteria (mass, pI, and retention time) reinforce the ID. Similar examples were located 


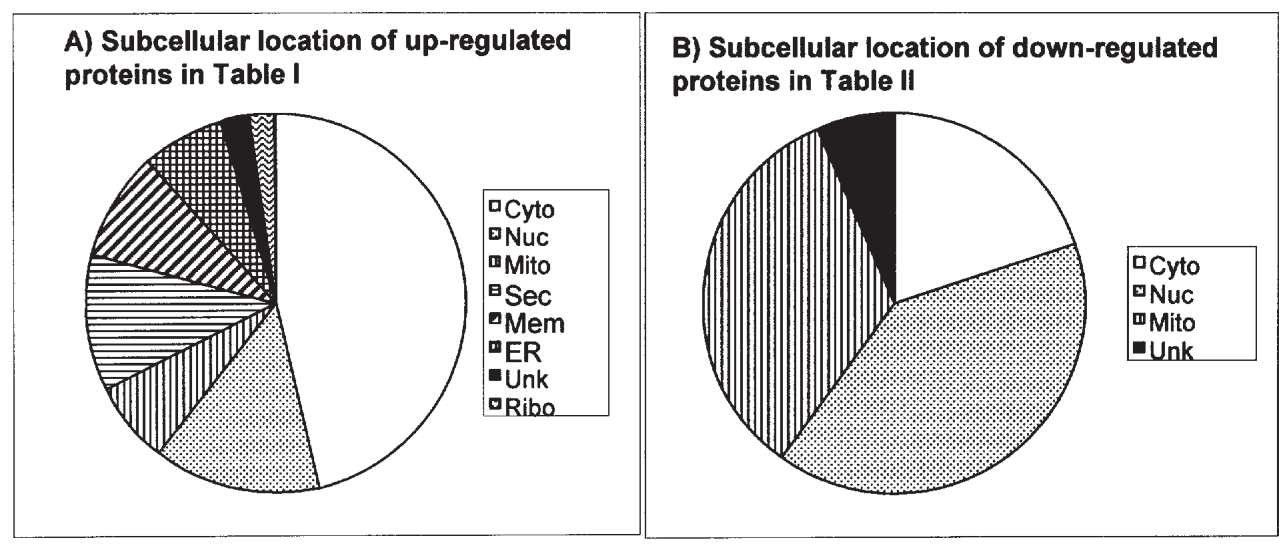

Figure 3. Subcellular locations of up- and down-regulated proteins. Cyto, cytoplasmic; Nuc, nuclear; Mito, mitochondrial; Sec, secretory; Mem, membrane; ER, endoplasmic reticulum; Unk, unknown; Ribo, ribosomal.

for phosphorylated proteins as well. Detected mass shifts of +42 or +80 Da were included in theoretical masses even if the PTM was not explicitly listed in the database. Although hypothetical, these apparent post-translational modifications allowed mass correlations and quantitation that might not otherwise be observed. In the process of making comparisons between cell lines, efforts focused on discovering common features between the cell lines. A total of 239 common mass bands were detected of which 133 were confidently correlated to an identified protein. Of these observed proteins, 67 proteins and isoforms shown in Tables I and II changed with progression to malignancy in both CA1a and CA1d. These proteins are differentially expressed ( $>2$-fold) in both malignant cell lines compared to the premaligant AT1.

An initial attempt to understand the impact of the observed malignancy related changes was carried out by examining the subcellular locations of differentially expressed proteins. Based on SwissProt database entries the subcellular locations for identified proteins are shown in Fig. 3. Cytosolic and nuclear proteins make up the majority of up-regulated proteins, whereas most down-regulated proteins are located in the nucleus and mitochondria. This strongly suggested significant alterations to the cell cycle as well as structure and metabolism.

Differentially expressed proteins were also classified according to their functions as given by SwissProt. Despite the large number of detected proteins, many of these changes represent discrete categories of alterations. The first and most obvious are a broad group of structural changes as seen by changes in expression of cytokeratins, tubulin, and proteins related to actin remodeling, such as LIMK-1 and tropomyosin. Malignant cells also show evidence of stress adaptations by up-regulating protein disulfide isomerase, peroxiredoxin, and several heat shock proteins. Finally, there appear to be significant alterations to metabolism, as seen by the downregulation of several ATP synthase (ATPase) subunits indicating a downturn in oxidative phosphorylation.

Cytokeratins are a ubiquitous class of cytoskeletal structural proteins found in epithelial cells (among many other types). As reported previously, changes in CK expression have been noted in the MCF10 model (9). CK7 and CK8 were again detected as up-regulated, although it now appears CK17 is up-regulated as well. This is likely related to the analysis of multiple adjacent $\mathrm{pI}$ fractions in the present study which would minimize the impact of band broadening in the pI dimension. CK8 presence has been linked to aggressive phenotypes in both breast and non-small cell lung cancers. In breast cancer it is associated with positive node status, a strong indicator for metastasis and the corresponding poor prognosis (14). Large scale clinical tissue screen has also associated these cytokeratins with abnormal phenotypes, further suggesting their utility as markers (15).

Although ( $(3$ and $\gamma$ ) actin expression is only up-regulated in CA1a (data not shown), actin dynamics play a vital role in cell motility and rigidity. LIMK-1, up-regulated $21 \mathrm{x}$ and $2 \mathrm{x}$ in CA1a and CA1d respectively, participates in actin remodeling by phosphorylating and thereby deactivating cofilin, an actin depolymerizing protein. In MCF7 breast cancer cells, this resulted in a strong correlation to increased invasiveness, a key property for metastasis (16). In addition to the in vitro invasiveness assays, Yoshioka et al (16) showed a link between LIMK-1 and number and size of osteolytic lesions produced by MDA-MB-231 tumor cells in nude mice. $\beta$-tropomyosin (down-regulated 20x and 8x in CA1a and CA1d respectively) is also of interest in actin dynamics by promoting formation of actin 'stress fibers', which can serve to enhance cell rigidity. Taken together, all these changes strongly suggest the mechanisms by which atypical cells change shape and become more motile.

In order to surmount the various environmental and metabolic stressors tumors encounter, a number of specialized proteins aid in protein synthesis and preservation of cell function. GRP75 and GRP78, both members of the broader $70 \mathrm{kDa}$ heat shock protein (HSP70) family, are molecular chaperones that assist with protein folding and transport, conferring resistance to environmental stressors and playing a role in regulation of cell growth (17). Higher expression of HSP70s has been associated with various cancers, GRP78 in particular has been shown to be associated with resistance to chemotherapeutic agents and is up-regulated in ductal carcinoma in situ and invasive ductal carcinoma of the breast $(18,19)$. Additionally, in hepatocarcinomas GRP78 has been associated with increased tumor grade, tumor size, and microvascular invasion (20). Up-regulation of GRP75 increased malignancy of breast cancer cells (21) and antisense to GRP75 induces a senescence-like growth arrest in immortalized human cells (22). Protein disulfide isomerase, also called 


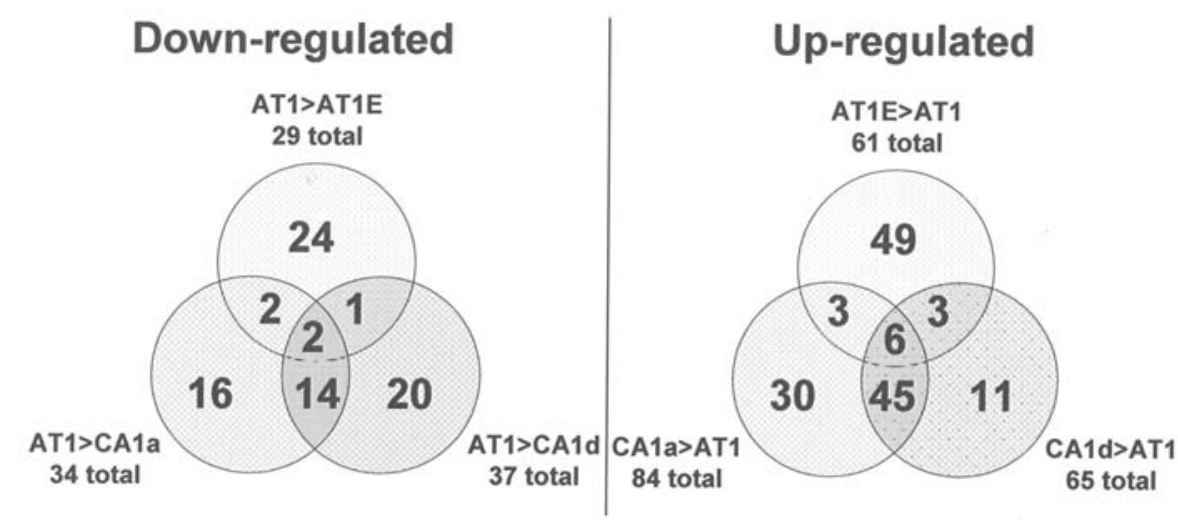

Figure 4. Venn diagrams of common up- and down-regulated proteins in MCF10AT1E, CA1a, and CA1d, relative to MCF10AT1. Circles show the number of proteins differentially expressed relative to AT1, with common proteins included in the intersecting areas.

GRP58 or ERp57, plays a role in protein folding by catalyzing the formation of disulfide bonds. It has been suggested that not only is protein disulfide isomerase up-regulated in various tumors, but it may play a role in the toxicity and specificity of the chemotherapeutic agent Mitomycin C (23).

The second group of proteins involved in stress adaptations is peroxiredoxin 2 (Prx II) and Mn-superoxide dismutase. Each plays a role in scavenging reactive oxygen species, with Mn-superoxide dismutase reducing superoxides to peroxides, and peroxiredoxin further reducing peroxides to water and alcohols. Mn-superoxide dismutase has been well characterized in colorectal carcinoma by Janssen and co-workers, indicating that not only is it up-regulated, but also associated with an negative clinical outcome (24). Peroxiredoxins have also been associated with proliferative and anti-apoptotic phenotypes, although the relationship has limited prognostic value (25).

Metabolic changes, particularly those related to oxidative phosphorylation and glycolysis, are another significant and long-standing area of interest for cancer researchers. Named for its discoverer Otto Warburg, the so-called 'Warburg Effect' is a general observation that tumors show evidence of a significant increase in anaerobic glycolysis (26). In the present work several chains of ATP synthase are seen to be down-regulated together with a corresponding increase in glycolytic enzymes including pyruvate kinase. This significant metabolic shift is believed to represent both an anti-apoptotic mechanism and an adaptation to the hypoxic environment present in most tumors (27). Down-regulation of oxidative metabolism not only reduces the amount of pro-apoptotic superoxide present in cells, but also deprives the cells of excess ATP needed to initiate apoptosis. Taken in conjunction with the increase in pyruvate kinase described here and the up-regulation of fructose bisphosphase aldolase, $\alpha$ enolase, and phosphoglycerate kinase described previously (9), both malignant cell lines have clearly adopted oncogenic glycolysis as a survival strategy (28).

\section{Discussion}

A comparison of these data with a previous study of changes induced by estradiol exposure further supports many of these findings (29). MCF10AT1 cells were incubated with estradiol
Table III. Proteins altered in malignant lines and in premalignant cells treated with estrogen relative to untreated MCF10AT1.

Up-regulated in AT1e2, CA1a, and CA1d

Thioredoxin-like protein p19 precursor (p19)

Tumor necrosis factor receptor superfamily member 10B precursor (TRAIL-R2)

Keratin, type II cytoskeletal 8 (CK8)

Stress-70 protein, mitochondrial precursor (GRP75)

$78 \mathrm{kDa}$ glucose-regulated protein precursor (GRP78)

LIM domain kinase 1 (LIMK-1)

Down-regulated in AT1e2, CA1a, and CA1d

BCL2/adenovirus E1B 19-kDa protein-interacting protein 3 (BNIP3)

ATP synthase $\alpha$ chain, mitochondrial precursor

Common in AT1e and CA1a

Up: Proto-oncogene C-crk (P38), elongation factor Tu

(EF-Tu), Cdc42-interacting protein 4 (TRIP10)

Down: Barrier to autointegration factor (BAF)

Common in AT1e and CA1d

Up: Galectin-1, Complexin 1, Annexin A5

Down: 14-3-3 Sigma

prior to harvesting and analysis using the 2-D liquid separation methodology described here. This estrogen induced proteome is referred to as MCF10AT1e2. A number of proteins that are differentially expressed between the untreated proteome (MCF10AT1) and the proteome following treatment with estrogen (MCF10AT1e2) have characteristics consistent with the development of a malignant phenotype (29). The degree of identification overlap between malignant related proteins and estrogen-induced proteins is displayed as the Venn diagrams in Fig. 4. As one might anticipate the malignant lines have more features in common, yet 12 up-regulated and 5 down-regulated proteins were shared between estradiol exposed cells and one or both of the malignant cell lines as seen in Table III. 
Several proteins described above as playing an important role in metabolism, structure, and stress adaptation in malignant cells also are induced by estrogen in the premalignant cells, further implicating these processes as highly relevant changes because estrogen treatment accelerates progression of premalignant AT1 xenografts in mice (30). Of particular note in this subset of common proteins are: a) BNIP3, an apoptosisinducing protein that binds BCL2, that was found to be downregulated 35-fold by estradiol in AT1 cells (29), was decreased to a similar extent with progression (Table II); b) LIM domain kinase-1 that is induced by estrogen in AT1 (29) and upregulated in both malignant lines may render cells resistant to apoptosis in addition to altering motility (31). Other proteins altered uniformly in malignant cells and estrogen treated premalignant cells are ATPase $\alpha$ chain (down-regulated) and GRP75, GRP78, CK8, and LIMK-1 (up-regulated). Bioenergetic changes have been observed in cells exposed to estrogen and there are numerous reports of estrogen-induced increases of reactive oxygen species in cells (reviewed in refs. 32,33 ). Induction of reactive oxygen species has been linked to changes in actin turnover together with an overall increase in invasiveness. These data support many of stress, actin remodeling, and metabolic changes described above.

MCF10AT cells express estrogen receptor (ER) (34) and estrogen accelerates progression of the premalignant xenograft lesions (30). Many human breast cancers are ER-negative and estrogen independent, but the early stages of disease in those individuals may have been estrogen responsive. We hypothesize that estrogen independent carcinomas (represented by the MCF10CA lines in the model) may constitutively express proteins that are altered by estrogen in earlier premalignant stages (such as MCF10AT1). The purpose of this study was to identify genes expressed constitutively in malignant MCF10CA variants that are also induced by estrogen in premalignant MCF10AT1 cells.

Although cancer progression is a well-studied process from a histological perspective, modern analytical techniques are finally able to shed light on specific proteins that are at least partly responsible for malignant phenotypes. $\mathrm{CF}$ and automated ESI-TOF data analysis allowed a study of an extended region of the acidic $\mathrm{pH}$ range in malignant and premalignant cells of the MCF10 human breast disease model. Not only was this study able to take advantage of the higher resolution and cleaner samples afforded by $\mathrm{CF}$, but analysis of multiple adjacent fractions allowed more thorough quantitation. This in-turn improved confidence in quantitation, ensuring fraction overlap would not negatively impact results.

Proteins altered in a single CA1 a line may be important for the malignant phenotype of that cell line. Galectin 1 (LGALS1), which is induced by estrogen and is up-regulated in MCF10CA1d but not in MCF10CA1a, mediates ras membrane anchorage and cell transformation and enhances ras signal transduction response to EGF (35). LGALS1 is also increased in human breast epithelial cells by overexpression of erbB2 (36). However, proteins altered in both malignant lines should be more fundamental to acquiring a malignant phenotype.

The combination of high performance separations together with mass spectrometry revealed 67 differentially expressed proteins in both MCF10Ca lines (16 down-regulated and 51 up-regulated) compared to the premalignant MCF10AT1 cells.
Of these, expression of 8 proteins was altered in the premalignant cells by estrogen ( 2 down-regulated and 6 upregulated). Of the eight proteins, one modulates the ras pathway. Mortalin (GRP75) may decrease ras levels and lower activity of downstream MAP kinase Erk2 (37). Many of the identified proteins are implicated in apoptotic signaling. A protein that is 35-fold lower after estrogen treatment and lower in both malignant lines is the hypoxia-regulated pro-apoptotic BCL2 interacting protein BNIP3 (38). Since BNIP3 induction of hypoxic cell death is inhibited by growth factors EGF and IGF (38), decreased BNIP3 expression may be an important factor in loss of growth factor dependence. LIM domain kinase-1 (LIMK-1) protein may inhibit caspase activation (31), GRP78 is overexpressed in malignant but not benign human breast and provides protection from apoptotic signals (18), and thioredoxin has been found to increase growth, increase sensitivity to growth factors and hormones, and inhibit apoptosis (39). Thioredoxin-like protein p19 displays thioredoxin activities and is a secretory protein (40) suggesting a possible autocrine or paracrine activity. TNFR10B, also known as TRAIL-R2 or DRK5, is up-regulated in CA1 lines and induced by estrogen. Although increased death receptor expression might be expected to render cells more susceptible to TRAIL induced apoptosis, TRAIL-R2 overexpression has been found to be associated with aggressive cancer and poor patient survival (41). TRAIL-R2 is also regulated by estrogen in MCF-7 cells but message and protein levels were both reduced in MCF-7 (42) rather than induced as seen with MCF10AT cells. Of the eight proteins identified as being constitutively altered in premalignant MCF10CA1 cells and estrogen responsive in premalignant MCF10AT1 cells, 1 effects ras signaling and 5 have been implicated in survival by inhibiting apoptosis.

\section{Acknowledgements}

We gratefully acknowledge support of this work by the National Cancer Institute under grants R01CA90503 (F.R.M., D.M.L.), as well as the National Institutes of Health under R01GM49500 (D.M.L.). We also acknowledge the National Science Foundation under grant DBI 99874 for funding of the MALDI-TOF-MS instrument used in this work.

\section{References}

1. Miller FR: Xenograft models of premalignant breast disease. J Mam Gland Biol 5: 379-381, 2000.

2. Miller FR, Soule HD, Tait L, Pauley RJ, Wolman SR, Dawson PJ and Heppner GH: Xenograft model of progressive human proliferative breast disease. J Natl Cancer Inst 85: 1725-1732, 1993.

3. Santner SJ, Dawson PJ, Tait L, Soule HD, Eliason J, Mohamed AN, Wolman SR, Heppner GH and Miller FR: Malignant MCF10CA1 cell lines derived from premalignant human breast epithelial MCF10AT cells. Breast Cancer Res Treat 65: 101-110, 2001.

4. Yan F, Subramanian B, Nakeff A, Barder TJ, Parus SJ and Lubman DM: A comparison of drug-treated and untreated HCT-116 human colon adenocarcinoma cells using a 2-D liquid separation mapping method based upon chromatofocusing $\mathrm{pI}$ fractionation. Anal Chem 75: 2299-2308, 2003.

5. Klose J and Kobalz U: Two-dimensional electrophoresis of proteins: an updated protocol and implications for a functional analysis of the genome. Electrophoresis 16: 1034-1059, 1995. 
6. Klose J: Protein mapping by combined isoelectric focusing and electrophoresis of mouse tissues. A novel approach to testing for induced point mutations in mammals. Humangenetik 26: 231-243, 1975.

7. Sluyterman LAA and Elgersma O: Chromatofocusing-isoelectricfocusing on ion-exchange columns. 1. General Principles. J Chromatogr 150: 17-30, 1978.

8. Kachman MT, Wang HX, Schwartz DR, Cho KR and Lubman DM: A 2-D liquid separation/mass mapping method for interlysate comparison of ovarian cancers. Anal Chem 74 : 1779-1791, 2002.

9. Hamler RL, Zhu K, Buchanan NS, Kreunin P, Kachman MT, Miller FR and Lubman DM: A two-dimensional liquid-phase separation method coupled with mass spectromic studies of breast cancer and biomarker identification. Proteomics 4: 562-577, 2004.

10. Buchanan NS, Hamler RL, Leopold PE, Miller FR and Lubman DM: Mass mapping of cancer cell lysates using twodimensional liquid separations, electrospray-time of flight-mass spectrometry, and automated data processing. Electrophoresis 26: 248-256, 2005.

11. Williams TL, Leopold P and Musser S: Automated postprocessing of electrospray LC/MS data for profiling protein expression in bacteria. Anal Chem 74: 5807-5813, 2002.

12. Baker PR and Clauser KR. http://prospector.ucsf.edu.

13. Boeckmann B, Bairoch A, Apweiler R, Blatter MC, Estreicher A, Gasteiger E, Martin MJ, Michoud K, O'Donovan C, Phan I, Pilbout S and Schneider M: The SWISS-PROT protein knowledge base and its supplement TrEMBL in 2003. Nucleic Acids Res 31: 365-370, 2003.

14. Brotherick L, Robson CN, Browell DA, Shenfine J, White MD, Cunliffe WJ, Shenton BK, Egan M, Webb LA, Lunt LG, Young JR and Higgs MJ: Cytokeratin expression in breast cancer: phenotypic changes associated with disease progression. Cytometry 32: 301-308, 1998

15. El-Rehim DMA, Pinder SE, Paish CE, Bell J, Blamey R, Robertson JFR, Nicholson RI and Ellis IO: Expression and coexpression of the members of the epidermal growth factor receptor (EGFR) family in invasive breast carcinoma. J Pathol 203: 661-671, 2003.

16. Yashioka K, Foletta V, Bernard $\mathrm{O}$ and Itoh $\mathrm{K}$ : A role for LIM kinase in cancer invasion. Proc Natl Acad Sci USA 100: 7247-7252, 2003.

17. Helmbrecht K, Zeise E and Rensing L: Chaperones in cell cycle regulation and mitogenic signal transduction: a review. Cell Prolif 33: 341-365, 2000.

18. Fernandez PM, Tabbara SO, Jacobs LK, Manning FCR, Tsangaris TN, Schwartz AM, Kennedy KA and Patierno SR: Overexpression of the glucose-related stress gene GRP78 in malignant but not benign human breast lesions. Breast Cancer Res Treat 59: 15-26, 2000.

19. Wulfkuhle JD, Sgroi DC, Krutzsch H, McLean K, McGarvey K, Knowlton M, Chen S, Shu HJ, Sahin A, Kurek R, Wallwiener D, Merino MJ, Petricoin EF, Zhao YM and Steeg PS: Proteomics of human breast ductal carcinoma in situ. Cancer Res 62: 6740-6749, 2002.

20. Lim SO, Park SG, Yoo J, Park YM, Kim H, Jang K, Cho JW, Yoo BC, Jung GH and Park CK: Expression of heat shock proteins (HSP27, HSP60, HSP70, HSP90, GRP78, GRP94) in hepatitis B virus-related hepatocellular carcinomas and dysplastic nodules. World J Gastroenterol 11: 2072-2079, 2005.

21. Wadhwa R, Takano S, Kaur K, Deocaris CC, Pereira-Smith OM, Reddell RR and Kaul SC: Upregulation of mortalin/mthsp70/ GRP75 contributes to human carcinogenesis. Int J Cancer 118: 2973-2980, 2006.

22. Wadhwa R, Takano S, Taira K and Kaul SC: Reduction in mortalin level by its antisense expression causes senescence-like growth arrest in human immortalized cells. J Gene Med 6: 439-444, 2004.

23. Celli CM and Jaismal AK: Role of GRP58 in mitomycin Cinduced DNA cross-linking. Cancer Res 63: 6016-6025, 2003.
24. Janssen AML, Bosman CB, Kruidenier L, Griffioen G, Lamers CBHW, van Krieken JHJM, van de Velde CJH and Verspaget HW: Superoxide dismutases in the human colorectal cancer sequence. J Cancer Res Clin Oncol 125: 327-335, 1999.

25. Noh DY, Ahn SJ, Lee RA, Kim SW, Park IA and Chae HZ: Overexpression of peroxiredoxin in human breast cancer. Anticancer Res 21: 2085-2090, 2001.

26. Warburg O: Metabolism of Tumors. Arnold Constable, London, 1930.

27. Cuezva JM, Krajewska M, De Heredia ML, Krajewski S, Santamaria G, Kim H, Zapata JM, Marusawa H, Chamorro M and Redd JC: The bioenergetic signature of cancer: a marker of tumor progression. Cancer Res 62: 6674-6681, 2002.

28. Dang CV and Semenza GL: Oncogenic alterations of metabolism. Trends Biochem Sci 24: 68-72, 1999.

29. Zhao J, Zhu K, Miller FR and Lubman DM: Proteomic analysis of estrogen response of premalignant human breast cells using a 2-D liquid separation/mass mapping technique. Proteomics 6: 3847-3861, 2006.

30. Shekhar MPV, Nangia-Makker P, Wolman SR, Tait L, Heppner GH and Visscher DW: Direct action of estrogen on sequence of progression of human preneoplastic breast disease. Am J Pathol 152: 1129-1132, 1998.

31. Yang E, Kim H, Lee J, Shin JS, Yoon H, Kim SJ and Choi IH: Overexpression of LIM kinase 1 renders resistance to apoptosis in PC1 2 cells by inhibition of caspase activation. Cell Mol Neurobiol 24: 181-192, 2004.

32. Felty Q, Xiong WC, Sun DM, Sarkar S, Singh KP, Parkash J and Roy D: Estrogen-induced mitochondrial reactive oxygen species as signal transducing messages. Biochemistry 44: 6900-6909, 2005

33. Felty Q and Roy D: Mitochondrial signals to nucleus regulate estrogen-induced cell growth. Med Hypotheses 64: 133-141, 2005.

34. Shekhar PVM, Chen ML, Werdell J, Heppner GH, Miller FR and Christman JK: Transcriptional activation of functional endogenous estrogen receptor gene expression in MCF10AT cells: a model for early breast cancer. Int J Oncol 13: 907-915, 1998

35. Paz A, Haklai R, Elad-Sfadia G, Ballan E and Kloog Y: Galectin-1 binds oncogenic Hras to mediate ras membrane anchorage and cell transformation. Oncogene 20: 7486-7493, 2001.

36. Elad-Sfadia G, Haklai R, Ballan E, Gabins HJ and Kloog Y: Galectin-1 augments ras activation and diverts ras signals to Raf-1 at the expense of phosphoinositide 3-kinase. J Biol Chem 277: 37169-37175, 2002 .

37. Wadhwa R, Yaguci T, Hasan MK, Taira K and Kaul SC: Mortalin-MPD (mevalonate pyrophosphate decarboxylase) interactions and their role in control of cellular proliferation. Biochem Biophys Res Commun 302: 735-742, 2003.

38. Kothari S, Cizeau J, McMillan-Ward E, Israels SJ, Bailes M, Ens K, Kirshenbaum LA and Gibson SB: BNIP3 plays a role in hypoxic cell death in human epithelial cells that is inhibited by growth factors EGF and IGF. Oncogene 22: 4734-4744, 2003.

39. Powis G, Mustacich D and Coon A: The role of redox protein thioredoxin in cell growth and cancer. Free Radic Biol Med 29: 312-322, 2000.

40. Liu F, Rong Y-P, Zeng L-C, Zhang X and Han Z-G: Isolation and characterization of a novel human thioredoxin-like gene hTLP19 encoding a secretory protein. Gene 315: 71-78, 2003.

41. McCarthy MM, Sznol M, DiVito KA, Camp RL, Rimm DL and Kluger HM: Evaluating expression and prognostic value of TRAIL-R1 and TRAIL-R2 in breast cancer. Clin Cancer Res 11: 5188-5194, 2005

42. Wang TTY and Jeng J: Coordinated regulation of two TRAILR2/KILLER/DR5 mRNA isoforms by DNA damaging agents, serum and 17ß-estradiol in human breast cancer cells. Breast Cancer Res Treat 61: 87-96, 2000. 